\title{
Moyamoya Disease
}

National Cancer Institute

\section{Source}

National Cancer Institute. Moyamoya Disease. NCI Thesaurus. Code C84895.

A rare inherited vascular disorder characterized by constriction of arteries at the base of the brain, resulting in the formation of collateral circulation in order to compensate for the constriction. The name "moyamoya" in Japanese means "puff of smoke" and derives from the characteristic radiog raphic appearance of the collateral vessels. 